\title{
Dealing with the storm: an overview of seizure precipitants and spontaneous seizure worsening in drug-resistant epilepsy
}

\author{
Emanuele Bartolini ${ }^{\mathrm{a}}$, Josemir W. Sander ${ }^{\mathrm{b}, \mathrm{c}}$ \\ a USL Centro Toscana, Neurology Unit, Nuovo Ospedale Santo Stefano, via suor Niccolina Infermiera 20, 59100 Prato, \\ Italy. Electronic address: emanuele.bartolini@uslcentro.toscana.it \\ b NIHR University College London Hospitals Biomedical Research Centre, UCL Queen Square Institute of Neurology, \\ London WC1N 3BG, \& Chalfont Centre for Epilepsy, Chalfont St Peter, SL9 0RJ, United Kingdom; Electronic \\ address: 1.sander@ucl.ac.uk \\ c. Stichting Epilepsie Instelligen Nederland (SEIN), Achterweg 5, Heemstede 2103 SW, the Netherlands.
}

Corresponding Author: Prof Ley Sander, Box 29, UCL Queen Square Institute of Neurology, London WC1N 3BG, UK. E-mail: 1.sander@ucl.ac.uk

Running title: Loss of seizure control

Number of tables: 2

Number of figures: 0

Word count: 2840

Number of references: 152 


\begin{abstract}
In drug-resistant epilepsy, periods of seizure stability may alternate with abrupt worsening, with frequent seizures limiting the individual's independence and physical, social and psychological well-being. Here we review the literature focusing_on different clinical scenarios related to seizure aggravation in people with drug-resistant epilepsy. The role of anti-seizure medication changes is examined, especially focusing on paradoxical seizure aggravation after increased treatment. The external provocative factors which unbalance the brittle equilibrium of seizure control are reviewed, distinguishing between unspecific triggering factors, specific precipitants and 'reflex' mechanisms. The chance of intervening surgical or medical conditions, including somatic comorbidities and epilepsy surgery failure, causing increased seizures is discussed. Spontaneous exacerbation is also explored, emphasizing recent findings on subject-specific circadian and ultradian rhythms. Awareness of external precipitants and understanding the subject-specific spontaneous epilepsy course may allow individuals to modify their lifestyles. It also allows clinicians to counsel appropriately and to institute suitable medical treatment to avoid sudden loss of seizure control.
\end{abstract}

Keywords: Drugs; Precipitants; Comorbidities; Surgery; Circadian and Ultradian cycles. 


\section{Introduction}

The prevalence of active epilepsy is between 4 and 10 per 1,000 people [1]. In most cases adequate anti-seizure treatment leads to sustained seizure freedom [2]. In about one third of people with epilepsy, however, seizures are drug-resistant, enduring despite optimal treatment. Most people with pharmaco-resistant epilepsy encounter periods of stability, with rare seizures or none at all, as well as periods with loss of seizure control. To disentangle seizure worsening due to specific provocative factors from a spontaneously fluctuating epilepsy course may be challenging. Loss of seizure control constantly hinders the ability to work or attend social events and often requires emergency treatment or hospitalization with additional health costs. We focus on different scenarios leading to seizure precipitation and discuss the possible predictable and unpredictable factors triggering seizure exacerbation in people with chronic epilepsy.

\section{Methods}

We performed a PubMed / Medline search with the following terms: 'seizure precipitants', 'seizure aggravation', 'seizure worsening', 'seizure prediction', 'epilep* aggravation', 'epilep* worsening' up to February 2019. No language restrictions were applied. All items identified were assessed for relevance to the topic of the review, excluding those exclusively focused on people with new onset seizures.

Due to the heterogeneous definition of seizure worsening in the published studies, we evaluated all those reporting an abrupt change in seizure frequency/types, independent of the underlying etiology. In addition to the automated Medline query we also added selected references retrieved on PubMed, Google and Google scholar search engines as well as articles in the authors' personal files. We categorized the available data into four main clinical scenarios: Treatment changes; External provocative factors; Intervening surgical or medical conditions; Spontaneous exacerbation.

\subsection{Scenario 1: Treatment changes}

Drug-resistant epilepsy is a continuous challenge. It is essential that attending physicians enter a therapeutic alliance with the individual to define shared treatment goals. Seizure freedom is the main target, as a substantial improvement in quality of life is obtained only after seizures stop completely [3-5]. Individuals may, however, opt for merely reduced seizure frequency to avoid medication side effects related to treatment required for seizure freedom [5] or may wish to target particular disabling seizure types, such as convulsions.

Anti-seizure treatment should thus be tailored to the wishes and needs of the individual, considering the unique clinical characteristics of that individual. Achieving the optimal balance between 
efficacy and tolerability often requires adjustments to the dosage of anti-seizure medication (ASM). A dose reduction may trigger sudden loss of seizure control in an individual but paradoxically a dose increase may also occasionally lead to seizure aggravation. One of the following conditions must be fulfilled to attribute seizure aggravation to a specific ASM: an increase in seizure frequency above that previously observed, temporally associated with the culprit drug and which reverses on withdrawal or dose reduction; demonstration of a consistent effect of a given drug in a specific seizure type or syndrome identification of any other factor (e.g., EEG features) which is predictive of drug-induced seizure deterioration; appearance of new seizure types in temporal association with a drug change[6].

Paradoxical seizure worsening may occur either as a result of a non-specific manifestation of drug intoxication or as a specific side effect in some syndromes [6]. In drug intoxication, seizure aggravation is sometimes dramatic and often accompanied by other signs of central nervous system toxicity (e.g. confusion, dizziness, brainstem and cerebellar signs). This has been reported particularly with phenytoin, which has zero-order kinetics and is prone to abrupt rises in drug levels after dosage increase, but it has also been described with other ASMs (e.g. phenobarbital, carbamazepine, tiagabine, vigabatrin, lamotrigine, gabapentin) independently from the underlying mechanism of action (reviewed in [6,7]). This is usually completely reversible after drug dosage reduction [6].

Conversely, drugs with particular mechanisms of action have been reported to induce or aggravate specific seizure types despite normal serum drug levels (table 1). Sodium channel blockers, especially carbamazepine, may trigger absences, tonic, atonic/negative myoclonus and myoclonic seizures [6,8-12], even in people who had previously experienced only tonic-clonic seizures $[9,10]$. Such effects may be particularly dramatic in children, who may develop status epilepticus $[8,13,14]$. Specific syndromes (e.g. absence epilepsy, juvenile myoclonic epilepsy, atypical benign Rolandic epilepsy, Landau-Kleffner, Dravet and Angelman syndromes) and EEG traits (e.g. generalized synchronous spike-and-wave activity, continuous spike-and-wave during sleep, multifocal abnormalities) are known to be particularly affected by sodium channel blocker-induced seizure precipitation $[6,8,15]$.

Vigabatrin and gabapentin can aggravate absences in idiopathic generalized epilepsies, sometimes leading to non-convulsive status epilepticus. Vigabatrin can also worsen tonic and myoclonic seizures, whilst gabapentin is especially detrimental to those with myoclonic seizures [16-18]. Valproate can aggravate seizures in the setting of a drug-specific idiosyncratic hyper-ammonemic encephalopathy. This is characterized by a progressive confusional state, seizure aggravation, non- 
epileptic myoclonus, vomiting and focal neurological deficits, especially in people with carnitine deficiency or congenital urea cycle enzymatic defects [19].

Benzodiazepines may also precipitate seizures, which seems counterintuitive as benzodiazepines are first-line drugs in status epilepticus. Abruptly increasing tonic seizures have, however, been reported in people with Lennox-Gastaut syndrome treated by intravenous benzodiazepines; this paradoxical effect has no clear explanation, is rare and has been reported exclusively during absence status epilepticus in individuals who had formerly experienced numerous other episodes of tonic status, sometimes provoked by other medications [20-22].

\subsection{Scenario 2: External provocative factors}

External seizure precipitants are mostly patient-reported and are highly subjective. Individuals may associate familiar and common triggers with the feeling of impending seizures rather than with seizures themselves, raising the possibility of false positives [23]. Overt seizures are the final expression of a waxing preictal phase while prodromes and auras are the initial symptoms perceived by the individual [24]. Auras are considered part of the ictal event, whilst prodromes (e.g. behavioral changes, cognitive disturbances, anxiety, fatigue) are believed to be preictal events not associated with EEG changes, appearing from a few minutes to two days before the seizure and lasting up to several hours, with obscure physiological background [25,26]. Therefore, seizure precipitants associated with prodromes/auras are not strictly false positives since they may correspond to states of high seizure susceptibility, which may not be followed by overt seizures due to the intervention of the brain homeostatic mechanisms [23].

Most people with epilepsy report at least one seizure precipitant, with emotional stress, sleep deprivation, and tiredness as the most frequent culprits, irrespective of the underlying syndrome $[27,28]$.

Emotional stress is reported as a seizure precipitant by over $80 \%$ of people with epilepsy [23]. This association declines with epilepsy duration, but is still reported by half of those with epilepsy for over 30 years [25]. Seizures may be precipitated by acute stress [26,27] and some people report being able to foresee seizures after minor or major stressors [28], especially when experiencing preictal mood changes [29,30]. Chronic stress may also affect epilepsy control $[26,31,32]$. People with stress-sensitive epilepsy exhibit a distinct brain response to stress hormones. There seems to be a positive correlation between cortisol levels and interictal discharges [33] and a negative correlation between cortisol levels and global functional connectivity on EEG [34]. Anxiety and depression are especially common in people whose epilepsy is worsened by emotional stress; half of these 
individuals pursue stress-reduction therapies (e.g. yoga, exercise and meditation) which appear to be beneficial in terms of seizure frequency $[26,32]$.

Sleep deprivation is reported as a seizure precipitant by about two thirds of people with epilepsy [23]. Sleeping for just one hour less than usual is an independent risk factor for seizure occurrence in unselected people acutely hospitalized for epileptic seizures [35]. People with generalized epilepsies, particularly juvenile myoclonic epilepsy, are especially prone to this [36-40]. Sleep deprivation seems less important in people with drug-resistant epilepsy who suffer daytime sleepiness and are therefore less likely to be exposed to sleep deprivation [41].

More than half of people with drug-resistant epilepsy report fatigue as a seizure precipitant [23], either as a non-specific preceding condition or as specific premonitory symptoms corresponding to a prodromal high-risk seizure state [29,42-45].

Alcohol intake as either chronic abuse or binge drinking is another common provoking factor. Intoxication by alcohol may trigger seizures due to a direct neurotoxic effect, or to the increased risk of head trauma and medical complications. Anti-seizure medication levels can also be substantially lowered in chronic users [49]. Excessive acute alcohol intake acts as a direct proconvulsant agent with a dose-dependent effect, whilst the effect of alcohol withdrawal on seizure occurrence is less clear and possibly confounded by the detrimental effect of chronic alcohol exposure [50]. Social drinking is rarely associated with seizure precipitation in focal epilepsy, but may affect seizure control in generalized syndromes, especially when associated with sleep deprivation [51]. People with epilepsy should therefore be counselled to use alcohol in only moderate amounts (less than two units /day). Those with higher intake should be warned of an increased risk of seizures, especially from 7 to $48 \mathrm{~h}$ after the last drink [49,52].

Illicit drug abuse may also negatively affect seizure control [23]. Cocaine, heroineheroin and opiates, amphetamines and substituted amphetamines including MDMA, are known to cause seizures in the general population and to exacerbate seizures in people with epilepsy [53-55]. The effect of cannabis abuse is less clear as there are reports of seizure worsening [56] and of improvements [57,58]. Overall, most do not report a substantial effect on seizures [49]. A particularly detrimental effect has been reported anecdotally in people with juvenile myoclonic epilepsy [49]. Such observations may be biased by the concomitant occurrence of sleep deprivation and missing medication in a syndrome which is sensitive to these two factors [49]. A distinction should be made between recreational cannabis use and the possible therapeutic advantages of selected compounds in epilepsy treatment [59]. Studies (reviewed in [59,60]) have demonstrated an anticonvulsant effect of CBD, the main non-psychoactive cannabis compound, leading the Food and Drug Administration to license its therapeutic use in Dravet and Lennox-Gastaut syndromes [61]. 
Conversely, the main psychoactive compound (THC) has mixed effects on the seizure threshold and is associated with detrimental cognitive and behavioral effects [62-65].

Seizure exacerbation may also result from exposure to very specific provocative stimuli with a 'reflex' mechanism. Such 'reflex seizures' are consistently and objectively induced by identifiable and specific triggers [66-68].

Seizures induced by photic stimulation are the most common 'reflex seizures' and occur mainly in idiopathic generalized epilepsies, but also in progressive myoclonic epilepsies, in epileptic encephalopathies and, more rarely, in temporal lobe epilepsy [69-72]. People with photosensitive seizures exhibit a characteristic EEG trait, the photoparoxysmal response. This is a highly heritable endophenotype which may also occur in healthy subjects, especially in relatives of people with photosensitive epilepsies [73-76].

The EEG photic stimulation clinical protocol is performed with stroboscopic intermittent stimuli at 1-60 Hz [77]. Studies performed after major seizure incidents in children and adults watching television and playing videogames [78-81] found low luminance deep-red flickers to be more provocative than conventional black-and-white stroboscopic stimulation, activating complex cortical and subcortical networks $[82,83]$. Specific broadcasting guidelines have been developed to limit the exposure to such activating stimuli, greatly enhancing the safety of people with epilepsy watching television and playing videogames. The introduction of Liquid Cristal Display monitors, rather than cathode ray tubes, may also have helped $[84,85]$. Nevertheless, potentially provocative stimuli may still be encountered in everyday life. In people with photosensitive epilepsies, preventive strategies include avoiding flashing lights, occluding one eye in front of provocative stimuli (e.g. stepping outdoors on a sunny day, objects with luminance variance), watching television from a distance of at least $2 \mathrm{~m}$ in a well-illuminated room and using color filtering or specific lenses [81,86,87].

More rarely, reflex seizures result from music, eating, swallowing, somatic sensory or proprioceptive stimuli, reading or hot water. In all these cases, preventive strategies consist of avoiding the specific stimulus, whenever possible [68]

Seizures induced by fever are not classed as reflex seizures, but there are specific epilepsy syndromes in which elevation of body temperature consistently precipitates seizures. Body heating whether caused by fever, warm water, ambient warmth, or physical exercise is a very specific and powerful seizure trigger in Dravet syndrome. This is caused by loss-of-function mutations affecting the temperature-sensitive SCN1A sodium channel [88]. Fever-sensitivity is also common in milder phenotypes associated with SCN1A mutations, such as generalized epilepsy with febrile seizures plus [89] and in girls with protocadherin 19 (PCDH19) mutations [90]. 


\subsection{Scenario 3: Intervening surgical or medical conditions}

In neurosurgical practice seizures are not rare. Individuals who have surgery for acquired brain lesions (e.g. brain tumors, vascular malformations, traumatic brain injuries) may experience seizures similar to those who undergo surgical treatment for drug-resistant epilepsy (i.e. epilepsy surgery). People with brain tumors are especially prone to pre-operative symptomatic seizures; drug-resistance is common in cortical-located tumors with low growth potential, defined as LongTerm Epilepsy Associated Tumors (LEATs; e.g. DNETs, gangliogliomas) [91-93] [94]. After surgery, 60-90\% of people with brain tumors become seizure free; this is particularly associated with LEATs, gross total resections, earlier surgical therapy, improved overall functional status and lack of pre-operative generalized seizures $[92,95]$. Nevertheless, seizures may also arise as a surgical complication. 'Early seizures' occur in the first week after craniotomy in up to one third of cases. This is irrespective of the occurrence of pre-operative seizures and of the underlying neuropathology, due to an immediate post-traumatic effect (cerebral edema, local inflammation, excitotoxic damage, oxidative stress, impairment of neuron metabolism). This may also sometimes lead to convulsive or non-convulsive status epilepticus [96-98]. The course of epilepsy can also be affected for the worse in individuals with tumor recurrence or incomplete resection [93,95,99]. Epilepsy surgery aims to control medical-resistant epilepsy by resecting or disconnecting the epileptogenic zone [100-102]. The epileptogenic zone is defined during presurgical work-up by merging clinical, neurophysiological and neuroimaging data in people with an overt epileptogenic lesion (e.g. hippocampal sclerosis, malformations of cortical development) and in those with normal brain imaging [102].

Early pre-operative seizures may complicate the outcome [103], but the prognosis of epilepsy surgery is largely favorable in the long-term with $70 \%$ of people experiencing greater than $50 \%$ seizure reduction at 10 years [104]. Nevertheless, post-operative epilepsy worsening in terms of increased seizure frequency may occur in up to $10 \%$ of cases. Rarely, individuals can develop seizure types they had not had previously, such as convulsions or status epilepticus [105]. Risk factors for seizure worsening following epilepsy surgery include extratemporal resections, incomplete resections, variable seizure semiologies and multiple recorded ictal patterns [105-107]. These individuals should be carefully followed-up, may require drug adjustments and may be offered surgical re-intervention after a comprehensive reassessment [108]. 
Comorbid medical conditions may also affect seizure control. About half of people with active epilepsy suffer at least one comorbid disease [109], some of which have a negative influence on epilepsy prognosis [110,111]. Migraine is associated with a reduced probability of seizure freedom [112], and psychiatric disorders to a higher risk of pharmaco-resistance [113] and to an unfavorable outcome after anterior temporal lobectomy [114]. Type 1 diabetes affects about $1 \%$ of people with drug-resistant epilepsy [115]. A shared genetic/autoimmune background has been postulated [115119]. In those with epilepsy - diabetes comorbidity, acute seizures provoked by hyperglycemia and hypoglycemia may occur, complicating the interpretation of the epilepsy course and drug management. Chronic glycemiaglycaemia fluctuations may also induce neuronal damage [120123], possibly facilitating seizures in the long-term.

We may also expect seizures to be precipitated by the same factors which cause abrupt seizures/status epilepticus in the general population, including acute metabolic disorders, stroke and infectious disorders [124].

Women with epilepsy may be especially exposed to fluctuations in seizure control during pregnancy and the menopause. Ideally, in those with drug-resistant epilepsy conception should be planned in order to minimize the exposure to ASMs during the first trimester. Drug management is particularly delicate, as a planned reduction of dosage/number of ASMs is sought to lower the risk of congenital malformation but this increases the likelihood of seizure worsening in the first trimester [125-127]. Early seizure deterioration may especially occur after withdrawal of valproate, which is burdened by the highest teratogenic potential $[127,128]$. Seizures may also worsen from the first to second or third trimesters (about 15\% of all pregnancies), requiring a reinforcement of the ASM regimen [126,129]. Women taking lamotrigine may be especially prone to seizure aggravation $[126,129]$ because the drug levels of this ASM decrease steeply over pregnancy, requiring careful monitoring and drug adjustments [130].

Menopause may also affect epilepsy, but the effect on seizure control is largely unpredictable. About $40 \%$ of women with chronic epilepsy report post-menopausal seizure worsening and $27 \%$ describe seizure improvement [131]. A direct effect of hormonal variations is likely as women with catamenial epilepsy tend to improve both during pregnancy [132] and after the menopause [133]. Intake of hormonal replacement therapy, however, negatively affects seizure control [134]. Therapeutic drugs taken for several medical conditions may also precipitate seizures in people with epilepsy. A systematic review classified therapeutic agents according to their intrinsic epileptogenic potential: meperidine, sevoflurane, clozapine and cyclosporine (high); propofol, maprotiline, tryciclic antidepressants, chlorambucil (intermediate); fluoroquinolones, carbapenems, bupropion and iodinated contrast media (low) [135]. Several other drugs have been reported as having a 
negative effect on seizures, either directly or by inducing the metabolism of ASMs. For example, ephedra dietary supplements have been associated with seizures due to the direct toxic effect of ephedrine [136], whilst exogenous estrogens administered for assisted reproduction might lead to seizure precipitation by lowering the seizure threshold and inducing glucuronidation in women taking lamotrigine [137].

\subsection{Scenario 4: Spontaneous exacerbation}

People with epilepsy may experience sudden spontaneous deterioration in seizure control. This is a difficult clinical scenario, as usually neither the clinician nor the individual concerned foresees the abrupt change in seizure frequency which may require emergency treatment.

The periodic exacerbation of seizures was reported in the first descriptions of epilepsy in 2000 B.C., in Mesopotamia, and interpreted in relation to moon cycles. In pre-Hippocratic Ancient Greece the 'sacred disease' was considered to wax and wane and be influenced by Selene, the Moon god [138]. Until the Middle Ages the term 'lunaticism' referred to epilepsy [139,140] (Table 2). The scientific approach has disentangled epilepsy from superstitious beliefs, while still acknowledging the existence of cyclical loss of epilepsy control [141,142]. More recent studies focusing on the longterm prognosis of epilepsy showed that up to one third of people with drug-resistant epilepsy show a relapsing-remitting course [2,106,107,143-148].

Prompted by such observations, several groups have attempted to develop machine learning algorithms based on various combinations of EEG, ECG, accelerometry, movement and audio and video parameters to predict seizure occurrence, with inconclusive results (reviewed in [149]). Recently, the relationship between EEG discharges and seizure occurrence at population and individual level has been investigated. Each individual with epilepsy seems to display a highly specific endogenous circadian rhythm of seizures and interictal spikes. About one third also exhibit subject-specific ultradian rhythmicity, with periodic breakthrough of seizure clusters [135]. Seizures are facilitated by the sleep-wake transition, but the effect of sleep on spike and seizure generation cannot completely explain circadian cyclicity as individuals may develop seizures at fixed hours, even though fully alert [150]. Clock (Circadian Locomotor Output Cycles Kaput) genes (e.g. $C L O C K$ and BMAL1) and circadian transcription factors (e.g. CLOCK-BMAL1) are likely to play a role, influencing cortical excitability and seizure threshold [151-154].

Monthly cyclicity may be partly related to the menstrual cycles in females [155], but males can also have monthly periodicity [156-158] and both may have non-monthly ultradian cycles, over multiple days, weeks or months $[154,159]$. 
The consistency of cortical-recorded spikes and seizure rhythmicity has been demonstrated longterm (up to 10 years) with a complex clinical/neurophysiological relationship. Interictal discharges may increase, decrease or remain unchanged before a single seizure [150,160], yet seizures preferentially occur during the rising phase of a multi-day spike cycle [160].

The knowledge of individual-specific circadian and ultradian cycles may help to foresee seizure occurrence. Implantation of long-term EEG monitoring devices has recently been suggested to gauge and forecast seizure risk, but technical challenges remain [161].

\section{Conclusions}

People with drug-resistant epilepsy have frequent challenges with seizures, whose onset and course are often unpredictable. Days of recurrent seizures may be extremely discouraging, greatly limiting self-confidence and independence. Identification of precipitating events allows individuals to anticipate abrupt worsening and to modify their lifestyles accordingly. From the clinician's viewpoint, comprehensive knowledge of the endogenous and exogenous provocative factors may allow appropriate counselling of the individual and institution of appropriate medical treatment. A deepened understanding of the cyclical course of epilepsy in each individual would allow further tailored care and prediction.

\section{Acknowledgements}

JWS is based at the NIHR University College London Hospitals Biomedical Research Centre, which receives a proportion of funding from the UK Department of Health's Research Centers funding scheme. He receives research support from the Dr Marvin Weil Epilepsy Research Fund and from the UK Epilepsy Society.

\section{Conflicts of interest}

JWS has received research funding from Eisai and UCB, personal fees from Eisai, UCB, GW and Zogenix Pharma, outside the submitted work. EB has no competing interests to declare. 

Table 1. Seizure worsening induced by Antiseizure medication

\begin{tabular}{|l|l|}
\hline Seizure type & Worsened or de novo induced by \\
\hline Typical and atypical absences & CBZ, GBP, LCM, LTG, OXC, PGB, PHT, TGB, VGB \\
\hline Myoclonic & CBZ, GBP, LTG, OXC, PGB, PHT, TGB, VGB \\
\hline Negative myoclonus and atonic seizures & CBZ, LTG \\
\hline Tonic seizures & BDZ, CBZ, OXC \\
\hline
\end{tabular}

BDZ, benzodiazepines; CBZ, carbamazepine; GBP, gabapentin; LCM, lacosamide; LTG, lamotrigine; OXC, oxcarbazepine; PGB, pregabalin; PHT, phenytoin; TGB, tiagabine; VGB, vigabatrin

Table 2. Timeline of historical descriptions on the fluctuating course of epilepsy

\begin{tabular}{|l|l|}
\hline Historical period & Description \\
\hline 2000 BC, Mesopotamia & $\begin{array}{l}\text { Ancient Akkadian texts describe epilepsy as 'antasubbû' (the hand } \\
\text { of sin) brought about by the god of the moon [162] }\end{array}$ \\
\hline 718-612 BC, Babylonia & $\begin{array}{l}\text { Babylonians distinguish epilepsy with diurnal and nocturnal } \\
\text { seizure clusters [163] }\end{array}$ \\
\hline Pre-Hippocratic Greece & $\begin{array}{l}\text { People who offend Selene, the goddess of the moon, are afflicted } \\
\text { by periodic seizures [138] }\end{array}$ \\
\hline 400 BC, Hippocrates & $\begin{array}{l}\text { Precipitating factors of seizures: changes of the winds and } \\
\text { temperature, exposure of the head to the sun, crying, fear [138] }\end{array}$ \\
\hline Medieval times & $\begin{array}{l}\text { Epilepsy as a vengeance of the goddess of the moon. The waxing } \\
\text { moon supposedly heated the atmosphere surrounding the earth, } \\
\text { which in turn melted the human brain and provoked the attack } \\
{[164,165]}\end{array}$ \\
\hline Eighteenth Century (1739) & $\begin{array}{l}\text { Sir Hans Sloane wrote on the relationship between moon cycles } \\
\text { and seizure occurrence [166] }\end{array}$ \\
\hline Nineteenth Century (1857) & $\begin{array}{l}\text { First description of catamenial epilepsy by Sir Charles Locock at } \\
\text { the Queen Victoria Hospital, London [167] }\end{array}$ \\
\hline
\end{tabular}




\section{References}

[1] Sander JW. The epidemiology of epilepsy revisited. Curr Opin Neurol 2003;16:165-70. doi:10.1097/01.wco.0000063766.15877.8e.

[2] Sillanpää M, Jalava M, Kaleva O, Shinnar S. Long-Term Prognosis of Seizures with Onset in Childhood. New England Journal of Medicine 1998;338:1715-22. doi:10.1056/NEJM199806113382402.

[3] Birbeck GL, Hays RD, Cui X, Vickrey BG. Seizure reduction and quality of life improvements in people with epilepsy. Epilepsia 2002;43:535-8.

[4] Piazzini A, Beghi E, Turner K, Ferraroni M, LICE Quality of Life Group. Health-related quality of life in epilepsy: findings obtained with a new Italian instrument. Epilepsy Behav 2008;13:119-26. doi:10.1016/j.yebeh.2008.02.017.

[5] Luoni C, Bisulli F, Canevini MP, De Sarro G, Fattore C, Galimberti CA, et al. Determinants of health-related quality of life in pharmacoresistant epilepsy: results from a large multicenter study of consecutively enrolled patients using validated quantitative assessments. Epilepsia 2011;52:2181-91. doi:10.1111/j.1528-1167.2011.03325.x.

[6] Perucca E, Gram L, Avanzini G, Dulac O. Antiepileptic Drugs as a Cause of Worsening Seizures. Epilepsia 1998;39:5-17. doi:10.1111/j.1528-1157.1998.tb01268.x.

[7] Chaves J, Sander JW. Seizure Aggravation in Idiopathic Generalized Epilepsies. Epilepsia 2005;46:133-9. doi:10.1111/j.1528-1167.2005.00325.x.

[8] Guerrini R, Belmonte A, Genton P. Antiepileptic drug-induced worsening of seizures in children. Epilepsia 1998;39 Suppl 3:S2-10.

[9] Lerman P. Seizures induced or aggravated by anticonvulsants. Epilepsia 1986;27:706-10.

[10] Shields WD, Saslow E. Myoclonic, atonic, and absence seizures following institution of carbamazepine therapy in children. Neurology 1983;33:1487-9.

[11] Abarrategui B, García-García ME, Toledano R, Parejo-Carbonell B, Gil-Nagel A, GarcíaMorales I. Lacosamide for refractory generalized tonic-clonic seizures of non-focal origin in clinical practice: A clinical and VEEG study. Epilepsy Behav Case Rep 2017;8:63-5. doi:10.1016/j.ebcr.2017.08.001.

[12] Gélisse P, Genton P, Velizarova R, Serafini A, Crespel A. Worsening of negative myoclonus by lamotrigine in a case of idiopathic focal epilepsy of children with long-term followup. Brain Dev 2012;34:248-50. doi:10.1016/j.braindev.2011.05.001.

[13] Snead OC, Hosey LC. Exacerbation of Seizures in Children by Carbamazepine. New England Journal of Medicine 1985;313:916-21. doi:10.1056/NEJM198510103131503. 
[14] Callahan DJ, Noetzel MJ. Prolonged absence status epilepticus associated with carbamazepine therapy, increased intracranial pressure, and transient MRI abnormalities. Neurology 1992;42:2198-201.

[15] Bauer J. Seizure-inducing effects of antiepileptic drugs: a review. Acta Neurologica Scandinavica 1996;94:367-77. doi:10.1111/j.1600-0404.1996.tb00047.x.

[16] Thomas P, Valton L, Genton P. Absence and myoclonic status epilepticus precipitated by antiepileptic drugs in idiopathic generalized epilepsy. Brain 2006;129:1281-92. doi:10.1093/brain/awl047.

[17] Asconapé J, Diedrich A, DellaBadia J. Myoclonus associated with the use of gabapentin. Epilepsia 2000;41:479-81.

[18] Panayiotopoulos CP, Agathonikou A, Sharoqi IA, Parker APJ. Vigabatrin aggravates absences and absence status. Neurology 1997;49:1467-1467. doi:10.1212/WNL.49.5.1467. [19] Segura-Bruna N, Rodriguez-Campello A, Puente V, Roquer J. Valproate-induced hyperammonemic encephalopathy. Acta Neurol Scand 2006;114:1-7. doi:10.1111/j.16000404.2006.00655.x.

[20] Tassinari CA, Dravet C, Roger J, Cano JP, Gastaut H. Tonic status epilepticus precipitated by intravenous benzodiazepine in five patients with Lennox-Gastaut syndrome. Epilepsia 1972;13:421-35.

[21] Bittencourt PR, Richens A. Anticonvulsant-induced status epilepticus in Lennox-Gastaut syndrome. Epilepsia 1981;22:129-34.

[22] DiMario FJ, Clancy RR. Paradoxical precipitation of tonic seizures by lorazepam in a child with atypical absence seizures. Pediatr Neurol 1988;4:249-51.

[23] Freestone DR, Karoly PJ, Cook MJ. A forward-looking review of seizure prediction. Curr Opin Neurol 2017;30:167-73. doi:10.1097/WCO.0000000000000429.

[24] Kotwas I, McGonigal A, Trebuchon A, Bastien-Toniazzo M, Nagai Y, Bartolomei F, et al. Self-control of epileptic seizures by nonpharmacological strategies. Epilepsy Behav 2016;55:15764. doi:10.1016/j.yebeh.2015.12.023.

[25] Scaramelli A, Braga P, Avellanal A, Bogacz A, Camejo C, Rega I, et al. Prodromal symptoms in epileptic patients: clinical characterization of the pre-ictal phase. Seizure 2009;18:246-50. doi:10.1016/j.seizure.2008.10.007.

[26] Schulze-Bonhage A, Haut S. Premonitory features and seizure self-prediction: artifact or real? Epilepsy Res 2011;97:231-5. doi:10.1016/j.eplepsyres.2011.09.026.

[27] Ferlisi M, Shorvon S. Seizure precipitants (triggering factors) in patients with epilepsy. Epilepsy \& Behavior 2014;33:101-5. doi:10.1016/j.yebeh.2014.02.019. 
[28] Nakken KO, Solaas MH, Kjeldsen MJ, Friis ML, Pellock JM, Corey LA. Which seizureprecipitating factors do patients with epilepsy most frequently report? Epilepsy \& Behavior 2005;6:85-9. doi:10.1016/j.yebeh.2004.11.003.

[29] Haut SR, Vouyiouklis M, Shinnar S. Stress and epilepsy: a patient perception survey. Epilepsy Behav 2003;4:511-4.

[30] Privitera M, Walters M, Lee I, Polak E, Fleck A, Schwieterman D, et al. Characteristics of people with self-reported stress-precipitated seizures. Epilepsy Behav 2014;41:74-7. doi:10.1016/j.yebeh.2014.09.028.

[31] Moshe S, Shilo M, Chodick G, Yagev Y, Blatt I, Korczyn AD, et al. Occurrence of seizures in association with work-related stress in young male army recruits. Epilepsia 2008;49:1451-6. doi:10.1111/j.1528-1167.2008.01591.x.

[32] Haut SR, Hall CB, LeValley AJ, Lipton RB. Can patients with epilepsy predict their seizures? Neurology 2007;68:262-6. doi:10.1212/01.wnl.0000252352.26421.13.

[33] Haut SR, Hall CB, Borkowski T, Tennen H, Lipton RB. Clinical features of the pre-ictal state: Mood changes and premonitory symptoms. Epilepsy \& Behavior 2012;23:415-21. doi:10.1016/j.yebeh.2012.02.007.

[34] Blanchet P, Frommer GP. Mood change preceding epileptic seizures. J Nerv Ment Dis 1986; 174:471-6.

[35] Webster A, Mawer GE. Seizure frequency and major life events in epilepsy. Epilepsia 1989;30:162-7.

[36] Moon H-J, Seo J-G, Park S-P. Perceived stress and its predictors in people with epilepsy. Epilepsy Behav 2016;62:47-52. doi:10.1016/j.yebeh.2016.06.038.

[37] van Campen JS, Hompe EL, Jansen FE, Velis DN, Otte WM, van de Berg F, et al. Cortisol fluctuations relate to interictal epileptiform discharges in stress sensitive epilepsy. Brain 2016;139:1673-9. doi:10.1093/brain/aww071.

[38] den Heijer JM, Otte WM, van Diessen E, van Campen JS, Lorraine Hompe E, Jansen FE, et al. The relation between cortisol and functional connectivity in people with and without stresssensitive epilepsy. Epilepsia 2018;59:179-89. doi:10.1111/epi.13947.

[39] Samsonsen C, Sand T, Bråthen G, Helde G, Brodtkorb E. The impact of sleep loss on the facilitation of seizures: A prospective case-crossover study. Epilepsy Res 2016;127:260-6. doi:10.1016/j.eplepsyres.2016.09.014.

[40] Del Felice A, Fiaschi A, Bongiovanni GL, Savazzi S, Manganotti P. The sleep-deprived brain in normals and patients with juvenile myoclonic epilepsy: a perturbational approach to measuring cortical reactivity. Epilepsy Res 2011;96:123-31. doi:10.1016/j.eplepsyres.2011.05.015. 
[41] Manganotti P, Bongiovanni LG, Fuggetta G, Zanette G, Fiaschi A. Effects of sleep deprivation on cortical excitability in patients affected by juvenile myoclonic epilepsy: a combined transcranial magnetic stimulation and EEG study. J Neurol Neurosurg Psychiatry 2006;77:56-60. doi:10.1136/jnnp.2004.041137.

[42] Canevini MP, Mai R, Di Marco C, Bertin C, Minotti L, Pontrelli V, et al. Juvenile myoclonic epilepsy of Janz: clinical observations in 60 patients. Seizure 1992;1:291-8. doi:10.1016/1059-1311(92)90039-4.

[43] da Silva Sousa P, Lin K, Garzon E, Sakamoto AC, Yacubian EMT. Self-perception of factors that precipitate or inhibit seizures in juvenile myoclonic epilepsy. Seizure 2005;14:340-6. doi:10.1016/j.seizure.2005.04.007.

[44] Panayiotopoulos CP, Obeid T, Tahan AR. Juvenile Myoclonic Epilepsy: A 5-Year Prospective Study. Epilepsia 1994;35:285-96. doi:10.1111/j.1528-1157.1994.tb02432.x. [45] Cobabe MM, Sessler DI, Nowacki AS, O’Rourke C, Andrews N, Foldvary-Schaefer N. Impact of sleep duration on seizure frequency in adults with epilepsy: a sleep diary study. Epilepsy Behav 2015;43:143-8. doi:10.1016/j.yebeh.2014.12.012.

[46] Haut SR, Lipton RB. Predicting seizures: a behavioral approach. Neurol Clin 2009;27:92540. doi:10.1016/j.ncl.2009.06.002.

[47] Schulze-Bonhage A, Kurth C, Carius A, Steinhoff BJ, Mayer T. Seizure anticipation by patients with focal and generalized epilepsy: a multicentre assessment of premonitory symptoms. Epilepsy Res 2006;70:83-8. doi:10.1016/j.eplepsyres.2006.02.001.

[48] Besag FMC, Vasey MJ. Prodrome in epilepsy. Epilepsy Behav 2018;83:219-33. doi:10.1016/j.yebeh.2018.03.019.

[49] Gordon E, Devinsky O. Alcohol and Marijuana: Effects on Epilepsy and Use by Patients with Epilepsy. Epilepsia 2001;42:1266-72. doi:10.1046/j.1528-1157.2001.19301.x.

[50] Ng SK, Hauser WA, Brust JC, Susser M. Alcohol consumption and withdrawal in newonset seizures. N Engl J Med 1988;319:666-73. doi:10.1056/NEJM198809153191102.

[51] Samsonsen C, Myklebust H, Strindler T, Bråthen G, Helde G, Brodtkorb E. The seizure precipitating effect of alcohol. Epilepsy Research 2018;143:82-9. doi:10.1016/j.eplepsyres.2018.04.007.

[52] Hauser WA, Ng SK, Brust JC. Alcohol, seizures, and epilepsy. Epilepsia 1988;29 Suppl 2:S66-78.

[53] Leach JP, Mohanraj R, Borland W. Alcohol and drugs in epilepsy: Pathophysiology, presentation, possibilities, and prevention: Alcohol, Drugs, and Seizures. Epilepsia 2012;53:48-57. doi:10.1111/j.1528-1167.2012.03613.x. 
[54] Hamerle M, Ghaeni L, Kowski A, Weissinger F, Holtkamp M. Cannabis and other illicit drug use in epilepsy patients. Eur J Neurol 2014;21:167-70. doi:10.1111/ene.12081.

[55] Alldredge BK, Lowenstein DH, Simon RP. Seizures associated with recreational drug abuse. Neurology 1989;39:1037-9.

[56] Keeler MH, Reifler CB. Grand mal convulsions subsequent to marijuana use. Case report. Dis Nerv Syst 1967;28:474-5.

[57] Consroe PF, Wood GC, Buchsbaum H. Anticonvulsant nature of marihuana smoking. JAMA 1975;234:306-7.

[58] Ellison JM, Gelwan E, Ogletree J. Complex partial seizure symptoms affected by marijuana abuse. J Clin Psychiatry 1990;51:439-40.

[59] Perucca E. Cannabinoids in the Treatment of Epilepsy: Hard Evidence at Last? Journal of Epilepsy Research 2017;7:61-76. doi:10.14581/jer.17012.

[60] Stockings E, Zagic D, Campbell G, Weier M, Hall WD, Nielsen S, et al. Evidence for cannabis and cannabinoids for epilepsy: a systematic review of controlled and observational evidence. Journal of Neurology, Neurosurgery \& Psychiatry 2018;89:741-53. doi:10.1136/jnnp2017-317168.

[61] Rubin R. The Path to the First FDA-Approved Cannabis-Derived Treatment and What Comes Next. JAMA 2018;320:1227. doi:10.1001/jama.2018.11914.

[62] Volkow ND, Baler RD, Compton WM, Weiss SRB. Adverse Health Effects of Marijuana Use. New England Journal of Medicine 2014;370:2219-27. doi:10.1056/NEJMra1402309.

[63] Rosenberg EC, Patra PH, Whalley BJ. Therapeutic effects of cannabinoids in animal models of seizures, epilepsy, epileptogenesis, and epilepsy-related neuroprotection. Epilepsy \& Behavior 2017;70:319-27. doi:10.1016/j.yebeh.2016.11.006.

[64] Devinsky O, Cilio MR, Cross H, Fernandez-Ruiz J, French J, Hill C, et al. Cannabidiol: Pharmacology and potential therapeutic role in epilepsy and other neuropsychiatric disorders. Epilepsia 2014;55:791-802. doi:10.1111/epi.12631.

[65] Maa E, Figi P. The case for medical marijuana in epilepsy. Epilepsia 2014;55:783-6. doi:10.1111/epi.12610.

[66] Proposal for revised classification of epilepsies and epileptic syndromes. Commission on Classification and Terminology of the International League Against Epilepsy. Epilepsia 1989;30:389-99.

[67] Fisher RS. The New Classification of Seizures by the International League Against Epilepsy 2017. Current Neurology and Neuroscience Reports 2017;17. doi:10.1007/s11910-017-0758-6.

[68] Okudan ZV, Ozkara C. Reflex epilepsy: triggers and management strategies. 
Neuropsychiatric Disease and Treatment 2018; Volume 14:327-37. doi:10.2147/NDT.S107669.

[69] Fisher RS, Harding G, Erba G, Barkley GL, Wilkins A. Photic- and Pattern-induced

Seizures: A Review for the Epilepsy Foundation of America Working Group. Epilepsia 2005;46:1426-41. doi:10.1111/j.1528-1167.2005.31405.x.

[70] Padmanaban V, Inati S, Ksendzovsky A, Zaghloul K. Clinical advances in photosensitive epilepsy. Brain Research 2019;1703:18-25. doi:10.1016/j.brainres.2018.07.025.

[71] Franceschetti S, Michelucci R, Canafoglia L, Striano P, Gambardella A, Magaudda A, et al. Progressive myoclonic epilepsies. Neurology 2014;82:405-11.

doi:10.1212/WNL.0000000000000077.

[72] Wolf P, Gooses R. Relation of photosensitivity to epileptic syndromes. J Neurol Neurosurg Psychiatry 1986;49:1386-1391.

[73] Italiano D, Striano P, Russo E, Leo A, Spina E, Zara F, et al. Genetics of reflex seizures and epilepsies in humans and animals. Epilepsy Res 2016;121:47-54.

doi:10.1016/j.eplepsyres.2016.01.010.

[74] Stephani U, Tauer U, Koeleman B, Pinto D, Neubauer BA, Lindhout D. Genetics of photosensitivity (photoparoxysmal response): a review. Epilepsia 2004;45 Suppl 1:19-23.

[75] Waltz S, Christen HJ, Doose H. The different patterns of the photoparoxysmal response--a genetic study. Electroencephalogr Clin Neurophysiol 1992;83:138-45.

[76] Trojaborg W. EEG abnormalities in 5,893 jet pilot applicants registered in a 20-year period. Clin Electroencephalogr 1992;23:72-8.

[77] Kasteleijn-Nolst Trenité D, Rubboli G, Hirsch E, Martins da Silva A, Seri S, Wilkins A, et al. Methodology of photic stimulation revisited: updated European algorithm for visual stimulation in the EEG laboratory. Epilepsia 2012;53:16-24. doi:10.1111/j.1528-1167.2011.03319.x.

[78] Takada H, Aso K, Watanabe K, Okumura A, Negoro T, Ishikawa T. Epileptic seizures induced by animated cartoon, "Pocket Monster.” Epilepsia 1999;40:997-1002.

[79] Takahashi T, Tsukahara Y. Pocket Monster incident and low luminance visual stimuli: special reference to deep red flicker stimulation. Acta Paediatr Jpn 1998;40:631-7.

[80] Harding GF. TV can be bad for your health. Nat Med 1998;4:265-7.

[81] Trenite DGAK-N, Silva AM, Ricci S, Binnie CD, Rubboli G, Tassinari CA, et al. VideoGame Epilepsy: A European Study. Epilepsia 1999;40:70-4. doi:10.1111/j.15281157.1999.tb00910.x.

[82] Bartolini E, Pesaresi I, Fabbri S, Cecchi P, Giorgi FS, Sartucci F, et al. Abnormal response to photic stimulation in juvenile myoclonic epilepsy: an. Epilepsia 2014;55:1038-47. doi:10.1111/epi.12634. 
[83] Takahashi T, Nakasato N, Yokoyama H, Tsukahara Y. Low-luminance visual stimuli compared with stroboscopic IPS in eliciting PPR in photosensitive patients. Epilepsia 1999;40 Suppl 4:44-9.

[84] Clippingdale S, Isono H. Photosensitivity, broadcast guidelines and video monitoring. IEEE SMC'99 Conference Proceedings. 1999 IEEE International Conference on Systems, Man, and Cybernetics (Cat. No.99CH37028), vol. 2, 1999, p. 22-7 vol.2. doi:10.1109/ICSMC.1999.825201. [85] Takahashi Y, Fujiwara T. Effectiveness of broadcasting guidelines for photosensitive seizure prevention. Neurology 2004;62:990-3.

[86] Capovilla G, Gambardella A, Rubboli G, Beccaria F, Montagnini A, Aguglia U, et al. Suppressive efficacy by a commercially available blue lens on PPR in 610 photosensitive epilepsy patients. Epilepsia 2006;47:529-33. doi:10.1111/j.1528-1167.2006.00463.x.

[87] Martins da Silva A, Leal B. Photosensitivity and epilepsy: Current concepts and perspectives-A narrative review. Seizure 2017;50:209-18. doi:10.1016/j.seizure.2017.04.001. [88] Verbeek NE, Wassenaar M, van Campen JS, Sonsma A, Gunning B, Knoers N, et al. Seizure precipitants in Dravet syndrome: What events and activities are specifically provocative compared with other epilepsies? Epilepsy \& Behavior 2015;47:39-44. doi:10.1016/j.yebeh.2015.05.008.

[89] Volkers L, Kahlig KM, Das JHG, van Kempen MJA, Lindhout D, Koeleman BPC, et al. Febrile temperatures unmask biophysical defects in $\mathrm{Na}_{\mathrm{v}} 1.1$ epilepsy mutations supportive of seizure initiation. The Journal of General Physiology 2013;142:641-53. doi:10.1085/jgp.201311042.

[90] Depienne C, Bouteiller D, Keren B, Cheuret E, Poirier K, Trouillard O, et al. Sporadic Infantile Epileptic Encephalopathy Caused by Mutations in PCDH19 Resembles Dravet Syndrome but Mainly Affects Females. PLoS Genetics 2009;5:e1000381. doi:10.1371/journal.pgen.1000381. [91] Bartolini E, Lenzi B, Vannozzi R, Parenti GF, Iudice A. Incidence and management of late postsurgical seizures in clinical practice. Turk Neurosurg 2012;22:651-5. doi:10.5137/10195149.JTN.6084-12.0.

[92] Chang EF, Potts MB, Keles GE, Lamborn KR, Chang SM, Barbaro NM, et al. Seizure characteristics and control following resection in 332 patients with low-grade gliomas. Journal of Neurosurgery 2008:227-35. doi:10.3171/JNS/2008/108/2/0227.

[93] Englot DJ, Berger MS, Barbaro NM, Chang EF. Predictors of seizure freedom after resection of supratentorial low-grade gliomas. A review. J Neurosurg 2011;115:240-4. doi:10.3171/2011.3.JNS1153.

[94] Luyken C, Blümcke I, Fimmers R, Urbach H, Elger CE, Wiestler OD, et al. The spectrum of 
long-term epilepsy-associated tumors: long-term seizure and tumor outcome and neurosurgical aspects. Epilepsia 2003;44:822-30.

[95] Englot DJ, Han SJ, Berger MS, Barbaro NM, Chang EF. Extent of Surgical Resection Predicts Seizure Freedom in Low-Grade Temporal Lobe Brain Tumors: Neurosurgery 2012;70:921-8. doi:10.1227/NEU.0b013e31823c3a30.

[96] Freund B, Probasco JC, Ritzl EK. Seizure incidence in the acute postneurosurgical period diagnosed using continuous electroencephalography. J Neurosurg 2018:1-7. doi:10.3171/2018.1.JNS171466.

[97] Kubota Y, Nakamoto H, Kawamata T. Nonconvulsive Status Epilepticus in the Neurosurgical Setting. Neurol Med Chir (Tokyo) 2016;56:626-31. doi:10.2176/nmc.ra.2016-0118. [98] Herman ST. Epilepsy after brain insult: targeting epileptogenesis. Neurology 2002;59:S21 26.

[99] Chaichana KL, Parker SL, Olivi A, Quiñones-Hinojosa A. Long-term seizure outcomes in adult patients undergoing primary resection of malignant brain astrocytomas. Clinical article. $\mathbf{J}$ Neurosurg 2009;111:282-92. doi:10.3171/2009.2.JNS081132.

[100] Lüders HO, Najm I, Nair D, Widdess-Walsh P, Bingman W. The epileptogenic zone: general principles. Epileptic Disord 2006;8 Suppl 2:S1-9.

[101] Talairach J, Bancaud J. Lesion, “irritative” zone and epileptogenic focus. Confin Neurol 1966;27:91-4.

[102] Jehi L. The Epileptogenic Zone: Concept and Definition. Epilepsy Currents 2018;18:12-6. doi:10.5698/1535-7597.18.1.12.

[103] Giridharan N, Horn PS, Greiner HM, Holland KD, Mangano FT, Arya R. Acute postoperative seizures as predictors of seizure outcomes after epilepsy surgery. Epilepsy Research 2016;127:119-25. doi:10.1016/j.eplepsyres.2016.08.026.

[104] Mohan M, Keller S, Nicolson A, Biswas S, Smith D, Osman Farah J, et al. The long-term outcomes of epilepsy surgery. PLOS ONE 2018;13:e0196274. doi:10.1371/journal.pone.0196274. [105] Sarkis RA, Jehi L, Bingaman W, Najm IM. Seizure worsening and its predictors after epilepsy surgery. Epilepsia 2012;53:1731-8. doi:10.1111/j.1528-1167.2012.03642.x.

[106] Sillanpää M, Schmidt D. Long-term outcome of medically treated epilepsy. Seizure 2017;44:211-6. doi:10.1016/j.seizure.2016.09.002.

[107] de Tisi J, Bell GS, Peacock JL, McEvoy AW, Harkness WFJ, Sander JW, et al. The longterm outcome of adult epilepsy surgery, patterns of seizure remission, and relapse: a cohort study. Lancet 2011;378:1388-95. doi:10.1016/S0140-6736(11)60890-8.

[108] Surges R, Elger CE. Reoperation after failed resective epilepsy surgery. Seizure 
2013;22:493-501. doi:10.1016/j.seizure.2013.04.020.

[109] Forsgren L. Prevalence of epilepsy in adults in northern Sweden. Epilepsia 1992;33:450-8.

[110] Gaitatzis A, Sisodiya SM, Sander JW. The somatic comorbidity of epilepsy: a weighty but often unrecognized burden. Epilepsia 2012;53:1282-93. doi:10.1111/j.1528-1167.2012.03528.x.

[111] Keezer MR, Sisodiya SM, Sander JW. Comorbidities of epilepsy: current concepts and future perspectives. Lancet Neurol 2016;15:106-15. doi:10.1016/S1474-4422(15)00225-2.

[112] Velioglu S, Boz C, Özmenoglu M. The Impact of Migraine on Epilepsy: A Prospective Prognosis Study. Cephalalgia 2005;25:528-35. doi:10.1111/j.1468-2982.2005.00912.x.

[113] Hitiris N, Mohanraj R, Norrie J, Sills GJ, Brodie MJ. Predictors of pharmacoresistant epilepsy. Epilepsy Res 2007;75:192-6. doi:10.1016/j.eplepsyres.2007.06.003.

[114] Kanner AM, Byrne R, Chicharro A, Wuu J, Frey M. A lifetime psychiatric history predicts a worse seizure outcome following temporal lobectomy. Neurology 2009;72:793-9. doi:10.1212/01.wnl.0000343850.85763.9c.

[115] Keezer MR, Novy J, Sander JW. Type 1 diabetes mellitus in people with pharmacoresistant epilepsy: Prevalence and clinical characteristics. Epilepsy Res 2015;115:55-7. doi:10.1016/j.eplepsyres.2015.05.008.

[116] Chou I-C, Wang C-H, Lin W-D, Tsai F-J, Lin C-C, Kao C-H. Risk of epilepsy in type 1 diabetes mellitus: a population-based cohort study. Diabetologia 2016;59:1196-203. doi:10.1007/s00125-016-3929-0.

[117] Sander JW, Novy J, Keezer MR. The intriguing relationship between epilepsy and type 1 diabetes mellitus. Diabetologia 2016;59:1569-70. doi:10.1007/s00125-016-3982-8.

[118] Saiz A, Blanco Y, Sabater L, González F, Bataller L, Casamitjana R, et al. Spectrum of neurological syndromes associated with glutamic acid decarboxylase antibodies: diagnostic clues for this association. Brain 2008;131:2553-63. doi:10.1093/brain/awn183.

[119] Dafoulas GE, Toulis KA, Mccorry D, Kumarendran B, Thomas GN, Willis BH, et al. Type 1 diabetes mellitus and risk of incident epilepsy: a population-based, open-cohort study.

Diabetologia 2017;60:258-61. doi:10.1007/s00125-016-4142-x.

[120] Verrotti A, Scaparrotta A, Olivieri C, Chiarelli F. Seizures and type 1 diabetes mellitus: current state of knowledge. Eur J Endocrinol 2012;167:749-58. doi:10.1530/EJE-12-0699.

[121] Tricò D, Herzog RI. Metabolic brain adaptations to recurrent hypoglycaemia may explain the link between type 1 diabetes mellitus and epilepsy and point towards future study and treatment options. Diabetologia 2017;60:938-9. doi:10.1007/s00125-017-4231-5.

[122] Herzog RI, Sherwin RS, Rothman DL. Insulin-induced hypoglycemia and its effect on the brain: unraveling metabolism by in vivo nuclear magnetic resonance. Diabetes 2011;60:1856-8. 
doi:10.2337/db11-0498.

[123] Hyllienmark L, Maltez J, Dandenell A, Ludvigsson J, Brismar T. EEG abnormalities with and without relation to severe hypoglycaemia in adolescents with type 1 diabetes. Diabetologia 2005;48:412-9. doi:10.1007/s00125-004-1666-2.

[124] Neligan A, Shorvon SD. Frequency and Prognosis of Convulsive Status Epilepticus of Different Causes: A Systematic Review. Arch Neurol 2010;67:931-40. doi:10.1001/archneurol.2010.169.

[125] Harden CL, Meador KJ, Pennell PB, Hauser WA, Gronseth GS, French JA, et al. Practice parameter update: management issues for women with epilepsy--focus on pregnancy (an evidencebased review): teratogenesis and perinatal outcomes: report of the Quality Standards Subcommittee and Therapeutics and Technology Assessment Subcommittee of the American Academy of Neurology and American Epilepsy Society. Neurology 2009;73:133-41.

doi:10.1212/WNL.0b013e3181a6b312.

[126] Battino D, Tomson T, Bonizzoni E, Craig J, Lindhout D, Sabers A, et al. Seizure control and treatment changes in pregnancy: observations from the EURAP epilepsy pregnancy registry. Epilepsia 2013;54:1621-7. doi:10.1111/epi.12302.

[127] Tomson T, Battino D. Teratogenic effects of antiepileptic drugs. Lancet Neurol 2012;11:803-13. doi:10.1016/S1474-4422(12)70103-5.

[128] Tomson T, Battino D, Bonizzoni E, Craig J, Lindhout D, Perucca E, et al. Withdrawal of valproic acid treatment during pregnancy and seizure outcome: Observations from EURAP. Epilepsia 2016;57:e173-177. doi:10.1111/epi.13437.

[129] EURAP Study Group. Seizure control and treatment in pregnancy: observations from the EURAP epilepsy pregnancy registry. Neurology 2006;66:354-60.

doi:10.1212/01.wnl.0000195888.51845.80.

[130] Pennell PB, Peng L, Newport DJ, Ritchie JC, Koganti A, Holley DK, et al. Lamotrigine in pregnancy: clearance, therapeutic drug monitoring, and seizure frequency. Neurology 2008;70:2130-6. doi:10.1212/01.wnl.0000289511.20864.2a.

[131] Abbasi F, Krumholz A, Kittner SJ, Langenberg P. Effects of menopause on seizures in women with epilepsy. Epilepsia 1999;40:205-10.

[132] Cagnetti C, Lattanzi S, Foschi N, Provinciali L, Silvestrini M. Seizure course during pregnancy in catamenial epilepsy. Neurology 2014;83:339-44.

doi:10.1212/WNL.0000000000000619.

[133] Harden CL, Pulver MC, Ravdin L, Jacobs AR. The effect of menopause and perimenopause on the course of epilepsy. Epilepsia 1999;40:1402-7. 
[134] Harden CL, Herzog AG, Nikolov BG, Koppel BS, Christos PJ, Fowler K, et al. Hormone replacement therapy in women with epilepsy: a randomized, double-blind, placebo-controlled study. Epilepsia 2006;47:1447-51. doi:10.1111/j.1528-1167.2006.00507.x.

[135] Ruffmann C, Bogliun G, Beghi E. Epileptogenic drugs: a systematic review. Expert Review of Neurotherapeutics 2006;6:575-89. doi:10.1586/14737175.6.4.575.

[136] Haller CA, Meier KH, Olson KR. Seizures reported in association with use of dietary supplements. Clin Toxicol (Phila) 2005;43:23-30.

[137] Mostacci B, Esposto R, Lello S, Bisulli F, Licchetta L, Tinuper P. Estrogen-related seizure exacerbation following hormone therapy for assisted reproduction in women with epilepsy. Seizure 2018;61:200-2. doi:10.1016/j.seizure.2018.08.024.

[138] Magiorkinis E, Sidiropoulou K, Diamantis A. Hallmarks in the history of epilepsy: Epilepsy in antiquity. Epilepsy \& Behavior 2010;17:103-8. doi:10.1016/j.yebeh.2009.10.023.

[139] Riva MA, Tremolizzo L, Spicci M, Ferrarese C, De Vito G, Cesana GC, et al. The disease of the moon: the linguistic and pathological evolution of the English term "lunatic." J Hist Neurosci 2011;20:65-73. doi:10.1080/0964704X.2010.481101.

[140] Cassano D, Colucci d'Amato C. "The moon" and "the blood": two emblematic symbols in headache and epilepsy according to scientific traditions of the Salerno Medical school and popular medicine in southern Italy. J Hist Neurosci 1992;1:97-110. doi:10.1080/09647049209525521.

[141] Gowers WR (William R. Epilepsy and other chronic convulsive diseases : their causes, symptoms, \& treatment. London : Churchill; 1881.

[142] Langdon-Down M, Brain WR. TIME OF DAY IN RELATION TO CONVULSIONS IN EPILEPSY. The Lancet 1929;213:1029-32. doi:10.1016/S0140-6736(00)79288-9.

[143] Callaghan B, Schlesinger M, Rodemer W, Pollard J, Hesdorffer D, Allen Hauser W, et al. Remission and relapse in a drug-resistant epilepsy population followed prospectively: DrugResistant Epilepsy Population. Epilepsia 2011;52:619-26. doi:10.1111/j.1528-1167.2010.02929.x.

[144] Choi H, Heiman GA, Munger Clary H, Etienne M, Resor SR, Hauser WA. Seizure remission in adults with long-standing intractable epilepsy: An extended follow-up. Epilepsy Research 2011;93:115-9. doi:10.1016/j.eplepsyres.2010.11.005.

[145] Neligan A, Bell GS, Sander JW, Shorvon SD. How refractory is refractory epilepsy? Patterns of relapse and remission in people with refractory epilepsy. Epilepsy Res 2011;96:225-30. doi:10.1016/j.eplepsyres.2011.06.004.

[146] Berg AT, Levy SR, Testa FM, D’Souza R. Remission of epilepsy after two drug failures in children: a prospective study. Ann Neurol 2009;65:510-9. doi:10.1002/ana.21642.

[147] Somerville ER. Aggravation of partial seizures by antiepileptic drugs: is there evidence from 
clinical trials? Neurology 2002;59:79-83.

[148] Shorvon SD, Sander JW. Temporal patterns of remission and relapse in patients with severe epilepsy. In: Schmidt D, Morceli P, editors. Intractable Epilepsy: experimental and clinical aspects, New York: Raven Press; 1986, p. 13-23.

[149] Ramgopal S, Thome-Souza S, Jackson M, Kadish NE, Sánchez Fernández I, Klehm J, et al. Seizure detection, seizure prediction, and closed-loop warning systems in epilepsy. Epilepsy \& Behavior 2014;37:291-307. doi:10.1016/j.yebeh.2014.06.023.

[150] Karoly PJ, Freestone DR, Boston R, Grayden DB, Himes D, Leyde K, et al. Interictal spikes and epileptic seizures: their relationship and underlying rhythmicity. Brain 2016;139:1066-78. doi:10.1093/brain/aww019.

[151] Hofstra WA, de Weerd AW. The circadian rhythm and its interaction with human epilepsy: a review of literature. Sleep Med Rev 2009;13:413-20. doi:10.1016/j.smrv.2009.01.002.

[152] Li P, Fu X, Smith NA, Ziobro J, Curiel J, Tenga MJ, et al. Loss of CLOCK Results in Dysfunction of Brain Circuits Underlying Focal Epilepsy. Neuron 2017;96:387-401.e6. doi:10.1016/j.neuron.2017.09.044.

[153] Gachon F, Fonjallaz P, Damiola F, Gos P, Kodama T, Zakany J, et al. The loss of circadian PAR bZip transcription factors results in epilepsy. Genes Dev 2004;18:1397-412. doi:10.1101/gad.301404.

[154] Khan S, Nobili L, Khatami R, Loddenkemper T, Cajochen C, Dijk D-J, et al. Circadian rhythm and epilepsy. The Lancet Neurology 2018;17:1098-108. doi:10.1016/S14744422(18)30335-1.

[155] Herzog AG, Fowler KM, Sperling MR, Massaro JM, Progesterone Trial Study Group. Distribution of seizures across the menstrual cycle in women with epilepsy. Epilepsia 2015;56:e5862. doi:10.1111/epi.12969.

[156] Bercel NA. The periodic features of some seizure states. Ann N Y Acad Sci 1964;117:55563.

[157] Bauer J, Burr W. Course of chronic focal epilepsy resistant to anticonvulsant treatment. Seizure 2001;10:239-46. doi:10.1053/seiz.2000.0499.

[158] Newmark ME, Penry JK. Catamenial epilepsy: a review. Epilepsia 1980;21:281-300.

[159] Karoly PJ, Goldenholz DM, Freestone DR, Moss RE, Grayden DB, Theodore WH, et al. Circadian and circaseptan rhythms in human epilepsy: a retrospective cohort study. The Lancet Neurology 2018;17:977-85. doi:10.1016/S1474-4422(18)30274-6.

[160] Baud MO, Kleen JK, Mirro EA, Andrechak JC, King-Stephens D, Chang EF, et al. Multiday rhythms modulate seizure risk in epilepsy. Nature Communications 2018;9:88. 
doi:10.1038/s41467-017-02577-y.

[161] Baud MO, Rao VR. Gauging seizure risk. Neurology 2018;91:967-73.

doi:10.1212/WNL.0000000000006548.

[162] Magiorkinis E, Sidiropoulou K, Diamantis A. Hallmarks in the History of Epilepsy: From Antiquity Till the Twentieth Century. In: Foyaca-Sibat H, editor. Novel Aspects on Epilepsy, InTech; 2011. doi:10.5772/19010.

[163] Wilson JV, Reynolds EH. Texts and documents. Translation and analysis of a cuneiform text forming part of a Babylonian treatise on epilepsy. Med Hist 1990;34:185-98.

[164] Diamantis A, Sidiropoulou K, Magiorkinis E. Epilepsy during the Middle Ages, the Renaissance and the Enlightenment. Journal of Neurology 2010;257:691-8. doi:10.1007/s00415009-5433-7.

[165] Temkin O. The Falling Sickness: A History of Epilepsy from the Greeks to the Beginnings of Modern Neurology. Johns Hopkins University Press; 1994.

[166] http://sloaneletters.com/the-moon-and-epilepsy/) n.d.

[167] Eadie M. Sir Charles Locock and potassium bromide. The Journal of the Royal College of Physicians of Edinburgh 2012;42:274-9. doi:10.4997/JRCPE.2012.317. 
